\title{
Diversity and Local Coadaptation of Escherichia coli and Coliphages From Small Ruminants
}

\author{
Felipe Molina ${ }^{1 *}$, Alfredo Simancas ${ }^{1 \dagger}$, Rafael Tabla ${ }^{2}$, Antonia Gómez ${ }^{2}$, Isidro Roa ${ }^{2}$ and \\ José Emilio Rebollo ${ }^{1}$ \\ ${ }^{1}$ Department of Biochemistry, Molecular Biology and Genetics, University of Extremadura, Badajoz, Spain, ${ }^{2}$ Dairy \\ Department, Technological Institute of Food and Agriculture - Scientific and Technological Research Centre of Extremadura, \\ Junta de Extremadura, Badajoz, Spain
}

OPEN ACCESS

Edited by:

Claudia Picozzi,

University of Milan, Italy

Reviewed by:

Andrea Isabel Moreno Switt,

Pontificia Universidad Católica

de Chile, Chile

Maite Muniesa

University of Barcelona, Spain

*Correspondence:

Felipe Molina

fmolina@unex.es

${ }^{\dagger}$ These authors have contributed equally to this work

Specialty section:

This article was submitted to

Food Microbiology,

a section of the journal

Frontiers in Microbiology

Received: 21 May 2020 Accepted: 17 September 2020

Published: 16 October 2020

Citation

Molina F, Simancas A, Tabla R, Gómez A, Roa I and Rebollo JE

(2020) Diversity and Local

Coadaptation of Escherichia coli and Coliphages From Small

Ruminants.

Front. Microbiol. 11:564522. doi: 10.3389/fmicb.2020.564522
Bacteriophages are highly specific predators that drive bacterial diversity through coevolution while striking tradeoffs among preserving host populations for long-term exploitation and increasing their virulence, structural stability, or host range. Escherichia coli and other coliform bacteria present in the microbiota of milk and during early ripening of raw milk cheeses have been linked to the production of gas, manifested by the appearance of eyes, and the development of off-flavors; thus, they might cause early blowing and cheese spoilage. Here, we report the characterization of coliphages isolated from manure from small ruminant farms and E. coli strains isolated from goat and sheep raw milk cheese. Additionally, the virulence and host range of locally isolated and laboratory collection phages were determined by comparing the susceptibility of $E$. coli strains from different sources. In agreement with the high genetic diversity found within the species E. coli, clustering analysis of whole-cell protein revealed a total of 13 distinct profiles but none of the raw milk cheese isolates showed inhibition of growth by reference or water-isolated coliphages. Conversely, 10 newly isolated phages had a broad host range (i.e., able to lyse $\geq 50 \%$ of bacterial hosts tested), thus exhibiting utility for biocontrol and only one cheese-isolated $E$. coli strain was resistant to all the phages. Whereas there was a high positive correlation between bacterial susceptibility range and lysis intensity, the phages virulence decreased as range increased until reaching a plateau. These results suggest local gene-for-gene coevolution between hosts and phages with selective tradeoffs for both resistance and competitive ability of the bacteria and host-range extension and virulence of the phage populations. Hence, different phage cocktail formulations might be required when devising long-term and short-term biocontrol strategies.

Keywords: phage-host coadaptation, Escherichia coli, biocontrol, raw milk cheese, phage therapy, tradeoffs in life history, dairy, bacteriophages

\section{INTRODUCTION}

The mysterious demise of Lord Carnarvon after entering Tutankhamen's tomb, although wrongly attributed to exposure to deadly mycotoxins (Cox, 2003), served to pose "the curse of the pharaoh theory," which postulates that extreme structural stability should favor the evolution of high virulence in parasites (Gandon, 1998; Roche et al., 2011). However, in bacteriophages, "life" history 
tradeoffs arise due to environmental stressors, proteins governing viral host range, and organization of the compact genome (Goldhill and Turner, 2014). Hence, successful phages must strike a balance between maximizing their virulence and preserving host populations for long-term exploitation, implying that evolving reduced virulence avoids eradicating the bacterial population or driving it toward total resistance. Whereas some phages exhibit a broad host range (Balogh et al., 2010), infecting different genera, the diverse nature and location of the host cell receptors usually entails high specificity of phagehost interactions (Bertozzi Silva et al., 2016). Moreover, phage extracellular existence produces a compromise among rapidly and successfully infecting hosts, withstanding environmental stressors (such as extreme $\mathrm{pH}$ and temperature) and spurious adsorption to inappropriate targets (Gallet et al., 2009; Keen, 2014). Like their predators, subtle tradeoffs between resistance and competitive ability determine the composition of bacterial populations when phages are present and hinder phage-resistant lineages from completely overcoming sensitive bacteria and eradicating predating phages (Bohannan and Lenski, 2000). Thus, the cost of resistance mutations is determined by the extent of resistance conferred, interactions with the abiotic environment and genetic backgrounds (Bohannan and Lenski, 1999). Resistance mutations to phage attacks might produce an evolutionary tradeoff in multi-drug resistant bacteria, whereby the selection of resistance to phages changes the efflux pump mechanism, causing increased sensitivity to several antibiotic classes (Chan et al., 2016). Whereas partial resistance is less costly than complete resistance (Lenski, 1988), mutations that confer cross-resistance to unrelated coliphages tend to be the most costly (Sen and Nikaido, 1991). Additionally, the level of T4 resistance in E. coli varies with the carbon source (Bohannan and Lenski, 1999) and temperature (Bohannan and Lenski, 2000).

In addition to these tradeoffs, coevolution shapes the diversity of phage-host communities. Negative frequencydependent selection elicits diversification of bacteria (to escape phages) and phages (to chase evolving bacteria). Hence, local adaptation creates modular networks of hosts and phages maintained by kill-the-winner ecological dynamics and a matching allele model (Flores et al., 2011). Accordingly, the cost of new mutations leading to infect/resist recently evolved hosts/phages would entail the loss of infectivity/resistance against ancestral genotypes (Agrawal and Lively, 2003). However, at small scales, phage-bacteria interaction networks typically show a nested structure, in which both hosts and phages can be ranked by their range of resistance and infectivity, respectively (Beckett and Williams, 2013). The nestedness derives from gene-for-gene processes, so hostrange expansion among phages evolves without compromising the ability to infect ancestral host genotypes, and likewise, the appearance of new resistance mutations in bacteria maintains resistance to past phages (Weitz et al., 2013). Experimental quantification of phage-host coevolutionary dynamics (Fortuna et al., 2019) has revealed that the nestedness decreases over time under fluctuating dynamics but increases under arms race dynamics. Moreover, when host-range is broad, phages and bacteria diversify more under arms race dynamics than under fluctuating dynamics. Since host range is a key property of phage therapy, it seems important to keep these considerations in mind while looking for effective bacteriophages.

Escherichia coli and other coliform bacteria are indicators of unfavorable hygienic conditions and fecal contamination (Molina et al., 2015), and some strains may cause severe disease in mammals and economic losses for food producers (Abe et al., 2002; Grad et al., 2012). E. coli exhibits remarkable genomic variation, and only $6 \%$ of its gene families are represented in every genome, comprising the core genome (Lukjancenko et al., 2010). Additionally, the high genomic similarity with related species suggests blurred species borders between Shigella spp. and E. coli (Gordienko et al., 2013). As a consequence of the resulting phenotypic variation, E. coli plays numerous biological roles, from laboratory-adapted workhorses to beneficial commensal or intracellular pathogens (Hendrickson, 2009). A substantial amount of antagonistic pleiotropy in evolved populations, as well as metabolic tradeoffs, are commonly found (Azevedo et al., 2016). These divergent niche adaptations hamper the achievement of broad host range phages for biocontrol of E. coli lineages.

Although cheese made from raw milk usually has intense flavor because of its diverse and highly variable microbiota (Montel et al., 2014), E. coli might cause early blowing and cheese spoilage (O'Sullivan and Cotter, 2017). Thus, the presence of $E$. coli during early ripening of raw milk cheeses has been linked to the production of gas, manifested by the appearance of eyes, and the development of off-flavors (Guggisberg et al., 2015; Tabla et al., 2016, 2018). Raw milk cheeses, particularly soft and semihard cheeses, have been associated with pathogenic E. coli outbreaks (Altekruse et al., 1998). Conversely, high levels of non-pathogenic E. coli in raw milk cheeses may contribute to the development of desirable characteristics of some of these products (Zago et al., 2007). The main advantage of using phages as biocontrol agents against undesired bacteria in cheese is that the specificity of phage-host spare the microbiota responsible for infusing natural flavors from being killed during treatment (Pujato et al., 2018). Conversely, the narrow host range limits the use of a single-phage treatments and multiple phage species are often mixed into cocktails (Abedon et al., 2017).

Here, we report the characterization of coliphages isolated from ewe feces and $E$. coli strains isolated from goat and sheep raw milk cheese. Whole-cell protein bacterial profiles and host-range clusters were compared. The virulence and host range of locally isolated and laboratory collection coliphages were determined by comparing the phage susceptibility of diverse E. coli strains. Several phages had a broad host range (i.e., able to lyse $\geq 50 \%$ of bacterial hosts tested), thus exhibiting utility for $E$. coli biocontrol. Our results suggest local gene-for-gene coevolution between hosts and phages, with selective tradeoffs for both resistance and competitive ability of the bacteria and host-range extension and virulence of the coliphage populations. 


\section{MATERIALS AND METHODS}

\section{Escherichia coli Strains and Bacteriophages Used as References in This Work}

The bacterial strains and coliphages used as references in this work are listed in Table 1. E. coli K-12 MG1655 was used for phage propagation. All bacterial cultures were grown in Luria broth (Pronadisa, Spain) at $37^{\circ} \mathrm{C}$ for $18-24 \mathrm{~h}$.

\section{Cheese Manufacturing and Sample Taking}

Two batches of soft ewe cheese (Torta del Casar PDO), semihard goat cheese (Ibores Cheese PDO) and semihard ewe cheese were manufactured $(\sim 0.650 \mathrm{~kg})$, each by two different local producers, following traditional methods. The soft variety was made according to the PDO regulation (Official Journal of the European Union [OJEU], 2002) with the addition of vegetable coagulant (Cynara cardunculus). Semihard varieties were made with the addition of calf rennet. "Ibores cheeses"

TABLE 1 | Bacterial strains and bacteriophages used as references in this study.

\begin{tabular}{ll}
\hline Strain or phage & Source and references \\
\hline Escherichia coli & \\
K12 (MG1655) & This lab (Molina et al., 1998) ATCC 700926 \\
MG1655 $\lambda+$ & This lab \\
B (Luria) & CECT 4201 \\
B/r & CECT 105 \\
Bi & CECT 4537 \\
BW6164 & CGSC 6759 \\
C (Sinsheimer) & ATCC 13706 \\
W1 (Waskman) & CECT 99 \\
W2 (Stoke) & CECT 727 \\
C600 & Gifted by Dr. Rouviere-Yaniv ATCC 23724 \\
GY752 & This lab (Sommer et al., 1998) \\
VIP45 $\lambda+$ & This lab (Dr. Miguel Vicente) \\
Shigella & \\
Shigella boydii & CECT 583 \\
Shigella flexneri 2a & CECT 585 \\
Shigella flexneri 2b & CECT 4804 \\
Shigella sonnei & CECT 4887 \\
Bacteriophages & \\
$\lambda$ & This lab, VIP45 strain induction \\
P1vir & NIG HR16 \\
T4 & NIG HR17 \\
T6 & NIG HR18 \\
SOM2, SOM3, SOM5, & Myoviridae isolated from seawater (Muniesa et al., 2002) \\
SOM8, SOM15 & \\
SCH2, SCH10 & Myoviridae isolated from sewage (Muniesa et al., 1999) \\
SCH5 & Siphoviridae isolated from sewage (Muniesa et al., 1999) \\
STER5 & Myoviridae isolated from river water (Muniesa et al., 1999) \\
&
\end{tabular}

ATCC, American Type Culture Collection (United States); CECT, Colección Española de Cultivos Tipo (Spain); CGSC, Coli Genetic Stock Center (United States); NIG, National Institute of Genetics (Japan). were made according to the PDO regulation (Official Journal of the European Union [OJEU], 2004). Semihard ewe cheese was made by adding lyophilized direct-to-vat mesophilic mixed culture (R-704, 50 units; Chr. Hansen, Hørsholm, Denmark) containing Lactococcus lactis subsp. cremoris and L. lactis subsp. lactis as the starter culture. Cheeses were brine salted $\left(16^{\circ} \mathrm{B}\right.$ at $10^{\circ} \mathrm{C}$ for $6 \mathrm{~h}$ ) and ripened at $10-12^{\circ} \mathrm{C}$ and $80 \%$ relative humidity for at least 60 days. From each of the batches, samples of milk, curd, and 1-, 2-, 4-, and 8-week-old cheese were taken and kept refrigerated for no longer than $8 \mathrm{~h}$ before analysis.

\section{Detection of Coliforms}

Preparation of test samples for microbiological examination was performed according to ISO 6887-5:2010. Milk samples were diluted in $9 \mathrm{~mL}$ of $0.1 \%(\mathrm{w} / \mathrm{v})$ peptone saline water at $30^{\circ} \mathrm{C}$ and subjected to serial dilutions. For curd and cheese, representative $10 \mathrm{~g}$ samples were placed into a sterile stomacher bag with $90 \mathrm{~mL}$ of sterile $2 \%(\mathrm{w} / \mathrm{v})$ trisodium citrate solution (Panreac, Barcelona, Spain) and blended for $5 \mathrm{~min}$ at $40^{\circ} \mathrm{C}$ in a stomacher (Stomacher Type 400; Seward, London, United Kingdom). Serial dilutions were prepared in $0.1 \%(\mathrm{w} / \mathrm{v})$ sterile peptone water and plated on E. coli coliform chromogenic medium (Pronadisa, Spain). Red to pink colonies were considered presumptive coliforms, and dark-blue to violet colonies were presumed E. coli.

\section{Isolation, Identification and Characterization of Escherichia coli}

Up to 10 presumptive E. coli isolates, identified by positive $\beta$-D-glucuronidase (MUG discs, Remel, United States) and $\beta$-D-galactosidase (ONPG discs, Oxoid, United Kingdom) activities, were randomly taken from each count plate and isolated by three alternate subcultures in nutrient broth (Oxoid Ltd., Hampshire, United Kingdom). Gram-negative, oxidasenegative and catalase-positive isolates were stored in LB medium (Pronadisa, Spain) containing 30\% (v/v) glycerol at $-80^{\circ} \mathrm{C}$.

Identification was performed with the aid of an EnteroPluriTest System (Liofilchem ${ }^{\circledR}$, Italy). Additionally, over $10 \%$ of the total number of isolates was analyzed with a Biolog Microbial ID System (Biolog, United States) according to the manufacturer's instructions. Strain characterization was performed by onedimensional sodium dodecyl sulfate-polyacrylamide gel electrophoresis (SDS-PAGE) of whole-cell proteins. Protein samples were prepared according to (Jackman, 1988) and analyzed by $10 \%$ SDS-PAGE by the method of (Laemmli, 1970). Gels were digitized using a densitometer (Bio-Rad GS800) and were analyzed with the aid of Phoretix 1D Pro software (Non-linear Dynamics, Newcastle, United Kingdom). The reference E. coli strain (ATCC 13706) was also included in the analysis. Protein patterns were corrected for gel distortion and gel-to-gel variation using a reference bacterial standard (Hafnia alvei, CECT 158). The similarity among digitized profiles was calculated using Pearson correlation, and an average linkage (UPGMA) dendrogram was derived from the similarity matrix. 


\section{Isolation of Bacteriophages}

A total of 16 sheep feces samples $(25 \mathrm{~g})$ were collected from four local ewe dairy farms (four samples per farm). Each sample was homogenized with $100 \mathrm{~mL}$ of phage suspension buffer $\left[1 \% 1 \% \mathrm{MgSO}_{4}\right.$ and $0.5 \mathrm{M} \mathrm{CaCl}_{2}$ (v/v)]. After $2 \mathrm{~h}$ of incubation at room temperature in a stomacher, samples were filtered and centrifuged at $8000 \times g$ for $10 \mathrm{~min}$. After adding a few drops of trichloromethane, the samples were incubated for $15 \mathrm{~min}$ at $37^{\circ} \mathrm{C}$ and centrifuged again at $8000 \times g$ for $10 \mathrm{~min}$. The supernatant was filtered through $0.22 \mu \mathrm{m}$ pore diameter filters (MF; Millipore) and stored at $4^{\circ} \mathrm{C}$ in glass vials with trichloromethane to kill the remaining bacteria. To detect the presence of coliphages in the supernatants, E. coli k-12 MG1655 was seeded using the double-layer method. Plates were divided into sectors, and aliquots of $20 \mu \mathrm{l}$ of phage supernatant were added to each sector. Once dried, plates were incubated at $37^{\circ} \mathrm{C}$ for $18 \mathrm{~h}$ to allow lytic zones appear. Phage strain isolation was initially carried out by spot assay as described elsewhere (Mirzaei and Nilsson, 2015). Later, to purify individual phages, the center of the plaques was pierced with a pipette tip dipped in $100 \mu \mathrm{L} \mathrm{LB}$ and diluted 1000 -fold. Finally, $10 \mu \mathrm{L}$ were mixed with $100 \mu \mathrm{L}$ of a fresh bacterial culture (OD600 $\mathrm{nm}=0.2-0.4$ ), incubated 10-15 min before transferring to fresh $2.5 \mathrm{~mL}$ heated $\left(50^{\circ} \mathrm{C}\right)$ soft agar $(0.6 \%)$ and plated on LB agar. The latter step was repeated at least twice until all plaques were homogenous. A total of 88 distinctive plaque-forming units at this stage were treated as different phages.

\section{Determination of Plaque Size and Adsorption Rate}

To measure plaque size, the phage strains were plated using E. coli strain MG1655 as the host strain and using double-layer agar as described elsewhere (Sambrook and Russell, 2001). After overnight incubation at $37^{\circ} \mathrm{C}$, plates were analyzed with an automatic colony counter (Scan 500, Interscience) set to illuminate from below and detect dark plaques over clear backgrounds. Sensitivity and minimal detectable size thresholds were adjusted manually when needed. The mean plaque diameter was determined after measuring at least 100 plaques.

Lambda phage (Table 1) adsorption to host cells was performed as described previously (Gabig et al., 2002). Host strains were grown in LB (Pronadisa, Spain) to an OD600 $\mathrm{nm}$ of 0.1 and incubated with $\lambda$ phage (multiplicity of infection: 0.1 ) in a water bath at $37^{\circ} \mathrm{C}$ with low constant shaking. At 5 , 10,15 , and $30 \mathrm{~min}$ after the infection, aliquots were centrifuged at $3000 \times g$ and $4^{\circ} \mathrm{C}$ for 5 min to allow attached phages to sediment along with bacteria while leaving free viral particles in the supernatant. The resulting samples were titrated for bacteriophages by triplicate plaque assays using six plates per assay. The decrease in the free phage titer normalized with respect to the initial phage titer indicates the adsorption rate. Theoretical phage adsorption kinetic data were taken from Storms and Sauvageau (2015).

\section{Cross-Streak and Host-Range Determination}

Phages $\left(10^{7} \mathrm{pfu} / \mathrm{mL}\right)$ were plated in nutrient agar (Oxoid Ltd., Hampshire, United Kingdom) following parallel streaks across the plate. Once dry, bacteria $\left(10^{8} \mathrm{pfu} / \mathrm{mL}\right)$ were plated perpendicular to phage streaks. After overnight incubation at $37^{\circ} \mathrm{C}$, a picture of each plate was digitized using a colony counter (Scan 500, Interscience). Zones of bacterial lysis were assessed with a scaling system, where 0 indicated no infection and 3 indicated a fully or nearly fully degraded bacterial lawn. Each infection assay was performed three times, and the average values were converted into a heat map.

\section{Transmission Electron Microscopy}

Transmission electron microscopy (TEM) was performed as previously described (Casey et al., 2015). Negative staining was performed using $2 \%(\mathrm{w} / \mathrm{v})$ uranyl acetate on freshly prepared ultrathin carbon films (Plano, Wetzlar, Germany). Grids were analyzed in a Tecnai G2 20 transmission electron microscope (FEI Thermo Fisher Scientific) at an acceleration voltage of $80 \mathrm{kV}$.

\section{Statistical Analysis}

Two-tailed (95\% confidence interval) non-parametric Spearman correlation tests were performed where indicated. To evaluate the correlation between whole-cell protein profiles and susceptibility range of raw milk cheese $E$. coli isolates, a Mantel test was carried out using distance matrices. To estimate the $p$-value, 9909 Monte Carlo simulations were carried out with a significance level of 5\%, 10,000 permutations, 6953 seeds (random numbers) and a confidence interval of $0.000-0.002$.

\section{RESULTS AND DISCUSSION}

\section{Characterization of Escherichia coli Isolated During Raw Milk Cheese Manufacturing and Ripening}

Escherichia coli was isolated on chromogenic medium from every raw milk sample (Figure 1A) ranging from 1.4 to $2.6 \log \mathrm{CFU} / \mathrm{g}$, whereas coliforms were from 1.5 to 3.5 orders of magnitude more abundant. These E. coli levels are noticeably low compared with those from soft or semisoft cheeses made from raw cow milk (Zago et al., 2007). In semihard cheeses, the maximum counts were detected during the first week of ripening, but in soft ewe cheese, the maximum was achieved during the second week. The numbers of $E$. coli decreased during ripening until their eventual elimination at 60 days. Strikingly, coliform levels did not decline noticeably in soft ewe cheese. Semihard cheese is usually ripened at $10^{\circ} \mathrm{C}$, acidifying the cheese during the first week, while soft cheeses ripen below $8^{\circ} \mathrm{C}$, which slows down the acidification and might explain these differences. E. coli has been reported as the predominant species toward the end of the ripening period in several cheese varieties (Gaya et al., 1987; Tornadijo et al., 1993; Freitas et al., 1996), showing its resistance to the adverse conditions of ripened cheeses. The extinction of $E$. coli might be due to competence with the microbial consortium, probably 
A
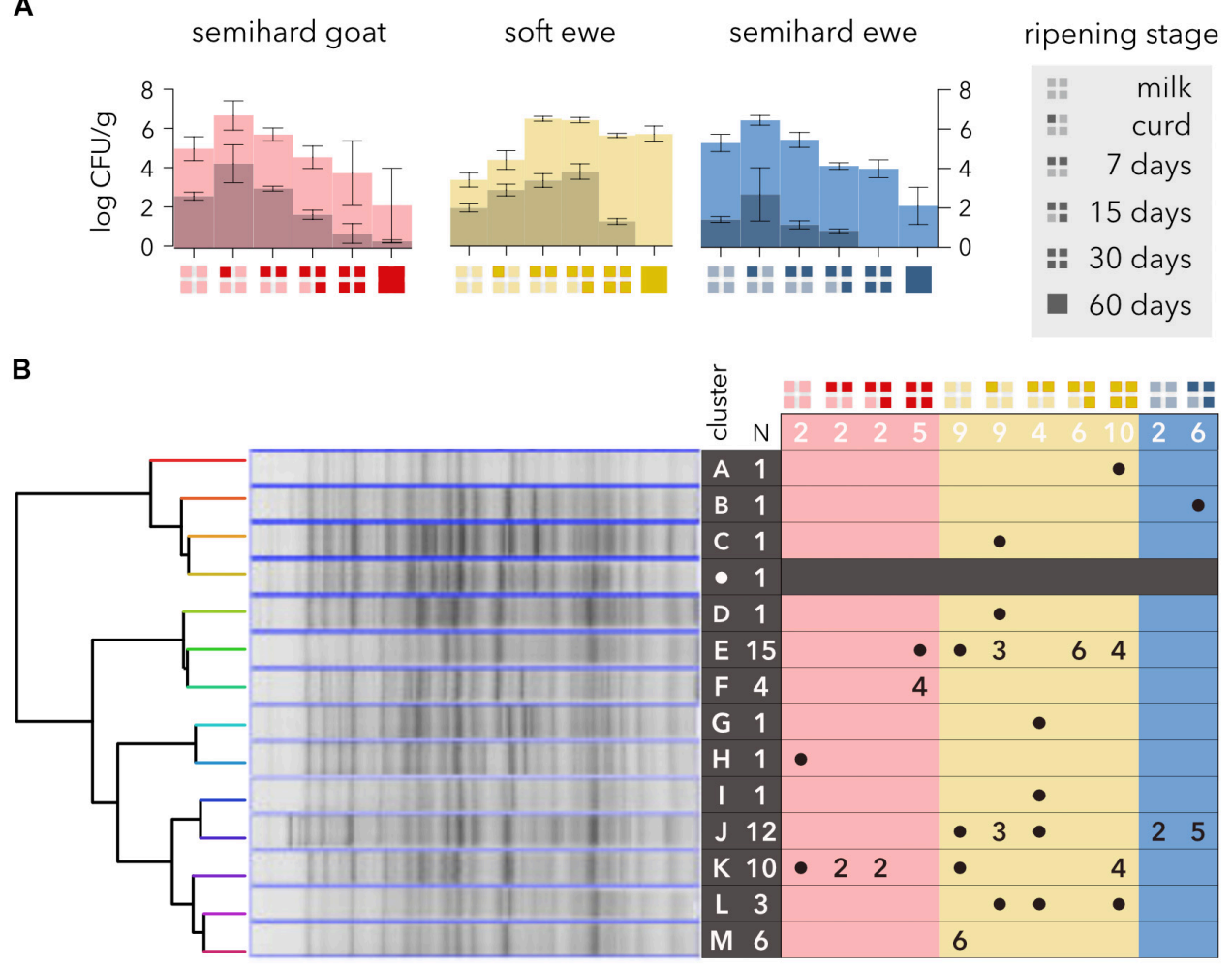

FIGURE 1 | Evolution and whole-cell protein profiling of Escherichia coli during different manufacturing and ripening stages of raw milk cheeses. (A) Changes in E. coli concentration (dark shading) and in total coliform bacterial levels (light shading). The semihard goat, soft ewe, and semihard ewe cheese varieties are represented by red, yellow, and blue, respectively. The ripening stages are represented by the code shown in the legend. (B) Hierarchical classification of $E$. coli strains based on their SDS-PAGE protein profiles. Strains were clustered from a similarity matrix, and a representative SDS-PAGE profile from each cluster is shown. A reference E. coli strain (CECT4622) is included (white dot on dark row). The total number of strains in each cluster is shown in row headers. The number of isolates from each sample is shown in column headers.

with $H$. alvei, which has been related to E. coli inhibition (DelbèsPaus et al., 2013; Callon et al., 2016), and is the predominant Enterobacteria after 30 days of ripening in these cheese varieties (Tabla et al., 2016, 2018).

Two-thirds (57 out of 86 ) of $\beta$-D-glucuronidase- and $\beta$-Dgalactosidase-positive colonies were confirmed as $E$. coli by two additional methods (data not shown) and selected for further characterization using one-dimensional SDS-PAGE of wholecell proteins (Figure 1B). Although chromogenic media have been validated to identify total coliforms and E. coli in foods (Turner et al., 2000; González et al., 2003), disagreement between different methods for the identification of $E$. coli and coliforms has been widely reported. Hence, whereas a high proportion of $\beta$-D-glucuronidase-negative $E$. coli strains has been described (Chang et al., 1989; Feng et al., 1991), $\beta$-D-glucuronidase activity is found in other bacterial species (Frampton and Restaino, 1993; Molina et al., 2015). Some presumptive E. coli isolates from raw milk cheese were eventually ascribed to the genus Klebsiella (Zago et al., 2007).

Clustering analysis of PAGE total protein profiles based on UPGMA clustering and cosine coefficient revealed at the $90 \%$ similarity level a total of 13 distinct protein profiles (Figure 1B). These results are in agreement with the high phenotypic diversity found in strains isolated from raw cow milk cheeses (Zago et al., 2007) and with the high genetic diversity found within the species E. coli (Lukjancenko et al., 2010). Three types of proteomics profiles could be distinguished: seven clusters comprised only one isolate, three others (F, L, and $\mathrm{M}$ ) comprised a few isolates (3-6) and the rest (E, J, and K) depicted higher numbers (10, 12 , and 15). Only the latter were found in two cheese varieties, but none of the clusters was ubiquitous enough to be found in every cheese sampled. Two clusters ( $\mathrm{E}$ and $\mathrm{K}$ ) were found in goat and soft ewe cheese, one ( $\mathrm{J}$ ) and both ewe cheeses and none in goat and semihard ewe cheese. The numbers of clusters found at different ripening stages were similar, four clusters at week 2 and 5 at the other ripening stages and two clusters ( $\mathrm{H}$ and $\mathrm{M}$ ) were detected only in milk, probably due to sensitivity to acidity, which may cause their disappearance during cheesemaking and ripening.

\section{Escherichia coli Strains Isolated From Cheese Are Not Lysed by Reference or Water-Isolated Coliphages}

To determine the sensitivity of $E$. coli strains to different coliphages, quantitative cross-streak assays were performed 
(Figure 2A). None of the raw milk cheese isolates representing each SDS-PAGE cluster (Figure 2B) showed inhibition of growth when cross-streaked against four reference $(\lambda, \mathrm{T} 4, \mathrm{~T} 6$, and $\mathrm{P} 1)$ or nine somatic coliphages (Table 1) isolated from sewage, river, or seawater (Muniesa et al., 1999, 2002). Conversely, most reference E. coli strains showed partial or total growth inhibition. Only a uropathogenic strain $(\mathrm{Bi})$, which produces a glycosaminoglycan-like capsular polysaccharide precursor to the anticoagulant pharmaceutical heparin (Cress et al., 2013), and an enteroaggregative diarrheagenic strain (W2) (Rahmouni et al., 2018) with long chain polysaccharide (Coleman et al., 1977) were resistant to all the phages. E. coli is a single species with strains having disparate lifestyles, from beneficial intestinal commensal to deadly pathogen (Rasko et al., 2008), as a result of divergent niche expansion millions of years ago (Hendrickson, 2009). Accordingly, the laboratory environment elicits its own ecological niche, which favors specific bacteriophage tactics to spread through laboratory-adapted strains, such as E. coli K-12 (Rotman et al., 2010). This variance might explain why cheeseisolated E. coli strains are not lysed by coliphages adapted to different host niches.

Determining the host range of a specific phage can be somewhat challenging because up to seven different hostrange types, each depending on phage successfully completing different steps of the infection process, have been described (Hyman and Abedon, 2010). Although host cell killing tends to be the key determination for phage therapy, host range is often determined by success or failure of adsorption. Under laboratory conditions, bacteria evolve high levels of CRISPR-based immunity against clonal populations of phages (Common et al., 2019; Broniewski et al., 2020). However, when infected with genetically diverse phage populations, the majority of the bacterial host population evolves a surface modification preventing phage adsorption and providing generalized defense against a broader range of phage genotypes (Broniewski et al., 2020).

The interaction of $\lambda$ phage with the maltose pore LamB represents the paradigm of initial phage-host binding (Chatterjee and Rothenberg, 2012) and several LamB mutations confer resistance to $\lambda$ phage infection without affecting maltodextrin transport (Andrews and Fields, 2020). To investigate whether the inability of $\lambda$ phage to lyse cheese strain cells was due to the lack of adsorption to the cell envelope or due to other mechanisms associated with productive growth (Maynard et al., 2010), the fraction of free $\lambda$ phages was monitored for $30 \mathrm{~min}$ (Figure 2C). Strikingly, while adsorption of $\lambda$ phage on sensitive control strains lay within the expected intervals, no decrease in the free phage titer was detected for any of the cheeseisolated strains. Additionally, the phage was expected to adsorb and inject its DNA into $\lambda$ lysogen cells despite their immunity to superinfection (Fogg et al., 2010). Although these results might be explained by modifications of the receptor LamB, previous work has shown that K-12 strains with mutations for lipopolysaccharide (LPS) synthesis reduce the number of surface
A

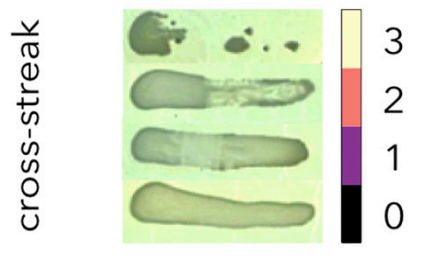

B

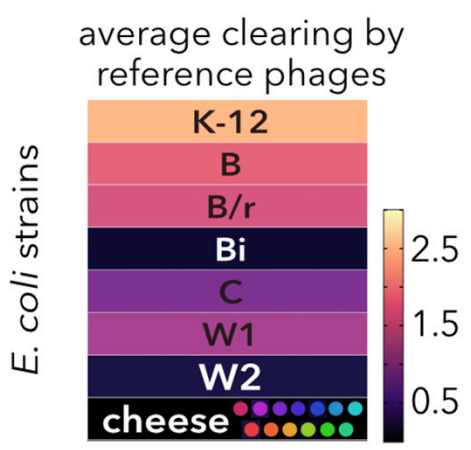

C

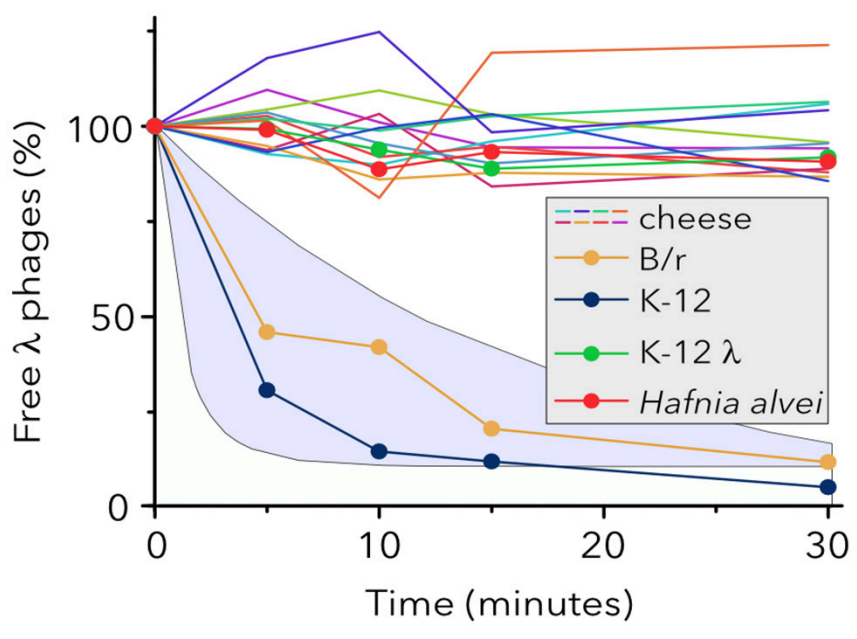

FIGURE 2 | Susceptibility of E. coli strains to different coliphages. (A) Cross-streak analysis of bacterial lysis. Zones of clearing were assayed with a scaling system where 0 indicates no lysis and 3 indicates a completely clear zone. Representative examples are shown. (B) Susceptibility of $E$. coli lineages to reference phages ( $\lambda$, T4, T6, and P1) and nine phage isolates from water sewage, rivers, and seawater (Table 1). One E. coli strain (data not shown) of each type was tested. The colored dots represent the SDS-PAGE protein profiles of raw milk-isolated strains. The average clearing values, after single infections with reference phages and two assays for each phage-host combination $(N=26)$, of each bacterial strain is shown by color shading. (C) Adsorption of $\lambda$ to different $E$. coli strains. Phage adsorption kinetics are shown as the average ( $N=3$ ) fraction of free phages remaining in solution over time and normalized with respect to the initial phage titer (100\%). Hafnia alvei and a lysogen strain (MG1655 $\lambda$ ) were used as controls. The shaded area shows two theoretical adsorption curves corresponding to the first-order model (top) and the adsorption efficiency model (bottom), as described in Storms and Sauvageau (2015). 
LamB proteins and (Randall, 1975) alter their arrangement (Yamada et al., 1981). In contrast, other studies have questioned whether the sole modification of LPS can severely impair cell infection by phage and explain the significant levels of resistance observed for deep-rough mutants (Fraser et al., 2006; Pagnout et al., 2019).

\section{Host Range of Coliphages Newly Isolated From Ewes}

To eliminate E. coli isolates from raw milk cheeses, ewe feces from local farms were used to isolate a total of 88 distinctive plaque-forming units. To identify the most effective and virulent phages, the plaque size and morphology were analyzed using a K-12 strain, and turbid plaque producers, which evince temperate phages, were discarded. With the remaining 26 virulent phages, a host-range matrix was built, and phages and bacteria were hierarchically clustered according to their infectivity and sensitivity profile, respectively (Figure $3 \mathbf{A}$ ). The phages producing larger plaques on the K-12 reference strain tended to produce a more intense clearing on highly sensitive hosts, but their host range was small. Conversely, phages yielding small plaques had extended host ranges. Since it has been shown that the plaque size of lambda phage is at its maximum when the lysis time is intermediate in length and that the adsorption rate and virion size negatively impact plaque size (Gallet et al., 2011), differences in plaque size cannot directly be correlated with virulence (Abedon and Yin, 2009). One of the seven phage clusters showed low variability (see cyan cluster on Figure 3A), comprising phages with identical infectivity profile; which could indicate re-isolation of the same phage. These phages were further analyzed by TEM (Figure 3B) and one of them was member of the morphotype A2 (Myoviridae with elongated head), but the rest showed the same basic morphotype B1 (Siphoviridae) with non-contractile tails (length, $\approx 140 \mathrm{~nm}$ ) and isometric heads (diameter, $\approx 55 \mathrm{~nm}$ ). Considering that Shigella and E. coli K-12 have a high degree of similarity we wanted to asses whether these coliphages could propagate on some Shigella lineages. Although none of the phages infected Shigella boydii, each produced a different lysis profile on Shigella flexneri and Shigella sonnei strains (Figure 3B); thus, re-isolation of coliphages seems unlikely.

Most of the 16 resulting bacterial clusters comprised E. coli isolates from a single source but different ripening stages. While only one E. coli strain, isolated (day 30) from soft ewe cheese, was resistant to all the phages, most reference bacteria were highly sensitive to the phages and were grouped in neighboring clusters. Unlike reference and water-isolated coliphages (Figure 2B), phages isolated from feces partially inhibited the proliferation of cheese-isolated E. coli. Furthermore, several phages had a broad range and were able to lyse more than $50 \%$ of the bacterial hosts tested. Despite being isolated from ewe feces, the coliphages were identified using a K-12 strain adapted to laboratory conditions (Molina et al., 1998). This procedure, although fairly standard, may have favored the isolation of narrower host range phages. Nonetheless, phages able to lyse $40 \%$ of hosts are considered to exhibit a broad host range (Fong et al., 2019). Alternatively, the use of multiple host strains from different sources could have led to the isolation of broader host range phages (Ross et al., 2016).

Although correlations between the bacterial sensitivity to phages and their proteomics profile (data not shown) are not easily detectable, the high clustering of goat and semihard ewe cheese isolates in the two groups for each category (Figure 3A) suggests that there could be a correlation between the whole-protein profile and the susceptibility to phages. To evaluate this hypothesis, the Mantel test was performed using the correlation matrix between the two dissimilarity matrices (Figure 3C). To this end, only cheese-isolated E. coli strains were considered. The $r$ statistic of 0.401 indicates that there is a moderate positive correlation between the matrices. The $p$-value of 0.001 indicates that these differences are statistically significant. Outer membrane proteins and LPS are typical phage receptors (Hantke, 2020), but other genes may also govern phage proliferation; thus, up to $57 \mathrm{E}$. coli genes when knocked out inhibit lambda phage's ability to replicate (Maynard et al., 2010). Consequently, complex correlations between protein composition and coliphages are not unexpected.

\section{Analysis of Life History Tradeoffs: Correlation Between Host Range and Virulence}

To evaluate whether the origin of $E$. coli strains correlates with the susceptibility range to phages and/or with the intensity of lysis, violin plots were generated (Figure 4A) from the host-range matrix (Figure 3A). Notably, both reference strain distributions yielded median values much higher than the values of the whole dataset (range: 77 versus 38\%, lysis: 2.01 versus 0.77 ). In contrast, $E$. coli strains isolated from goat cheese were lysed by the fewest phages (median $=15 \%$ ), and the phages able to proliferate produced the minimum clearing intensity (median $=0.67$ ). Negative effects on the physiology of $E$. coli cells might prevent the invasion of phage resistance mutations in sheep milk (Lenski, 1988). Ecological differences, such as different milk compositions (Raynal-Ljutovac et al., 2008), the cost of mutations conferring phage resistance (Sen and Nikaido, 1991), or the coevolution of coliphages and ewe isolates might explain the different susceptibility ranges in ewe and goat isolates. The microbiotas of raw milk from sheep and goats show different predominant Enterobacteria genera, with Citrobacter being most abundant in sheep and Pantoea in goats (Tabla et al., 2016, 2018). A recent comparative metagenomic analysis of fecal microbiota showed significant differences in Proteobacteria content between sheep $(>26.83 \%)$ and goats (>62.03\%) (Shabana et al., 2020). Neither cheesemaking technology nor stage of ripening seemed to influence the phage-sensitivity range or lysis intensity of cheese-isolated strains.

Whereas there is a high positive correlation (Spearman's $r=0.83$ ) between bacterial susceptibility range and lysis intensity (Figure 4B), the correlation between host range and virulence for the phages is negative and weaker $(r=-0.25)$. Notwithstanding some phages displaying narrow host range and low virulence, virulence tended to decrease as range increased until reaching 


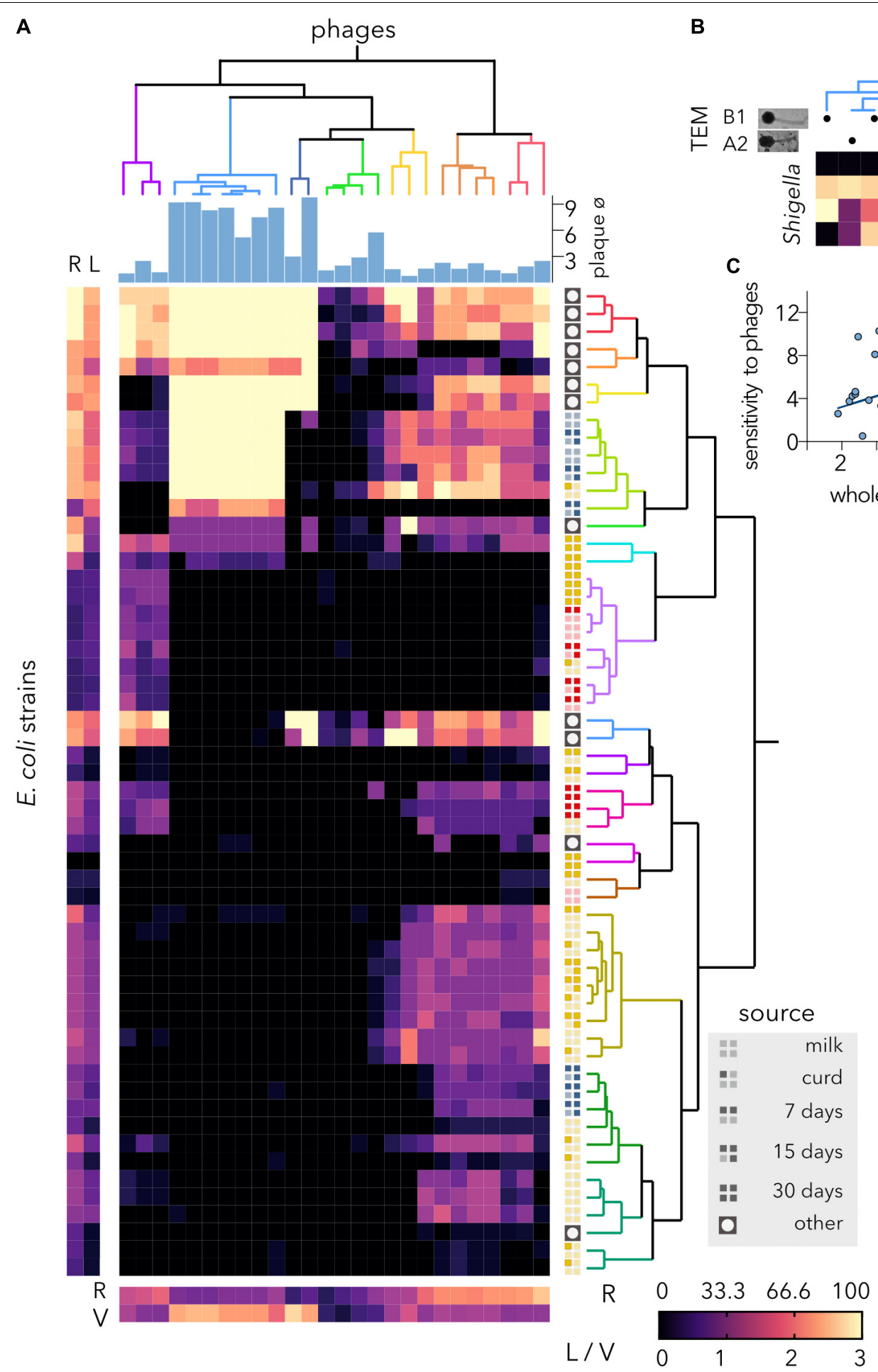

FIGURE 3 | Host range of virulent isolated phages. (A) The heatmap represents the lysis profiles of phages versus host $E$. coli strains. Phage infection is indicated after calculating the average clearing values of several experiments $(6>\mathrm{N}>2)$, where clearing varies between 1 and 3 ; $0=$ no lysis. The average values for each strain are shown on the left (bacteria) and bottom (phages). The hierarchical classifications of Escherichia coli strains and coliphages were performed using Ward's method. The source of each bacterial strain is shown. The plaque diameter ( $\mathrm{mm}$ ) measured after infecting strain MG1655 is shown for each phage. R, \% host range. The clearing is indicated as $L$ (lysis) for the bacteria and $V$ (virulence) for the phages. (B) Characterization of the coliphage cluster with the lowest infectivity variance. TEM, transmission electron microscopy; B1, Siphoviridae; A2, Myoviridae with elongated head. Lysis profiles of Shigella spp. strains. Sb, Shigella boydii; Sf 2A, Shigella flexneri 2A; Sf 2B, Shigella flexneri 2B; Ss, Shigella sonnei. (C) Correlation of SDS-PAGE and lysis profiles of cheese-isolated E. coli strains. Using the distance matrices, the correlation $(r=0.401)$ and statistical significance ( $p$-value $=0.001)$ at an alpha of 0.05 were computed by performing a Mantel test. 

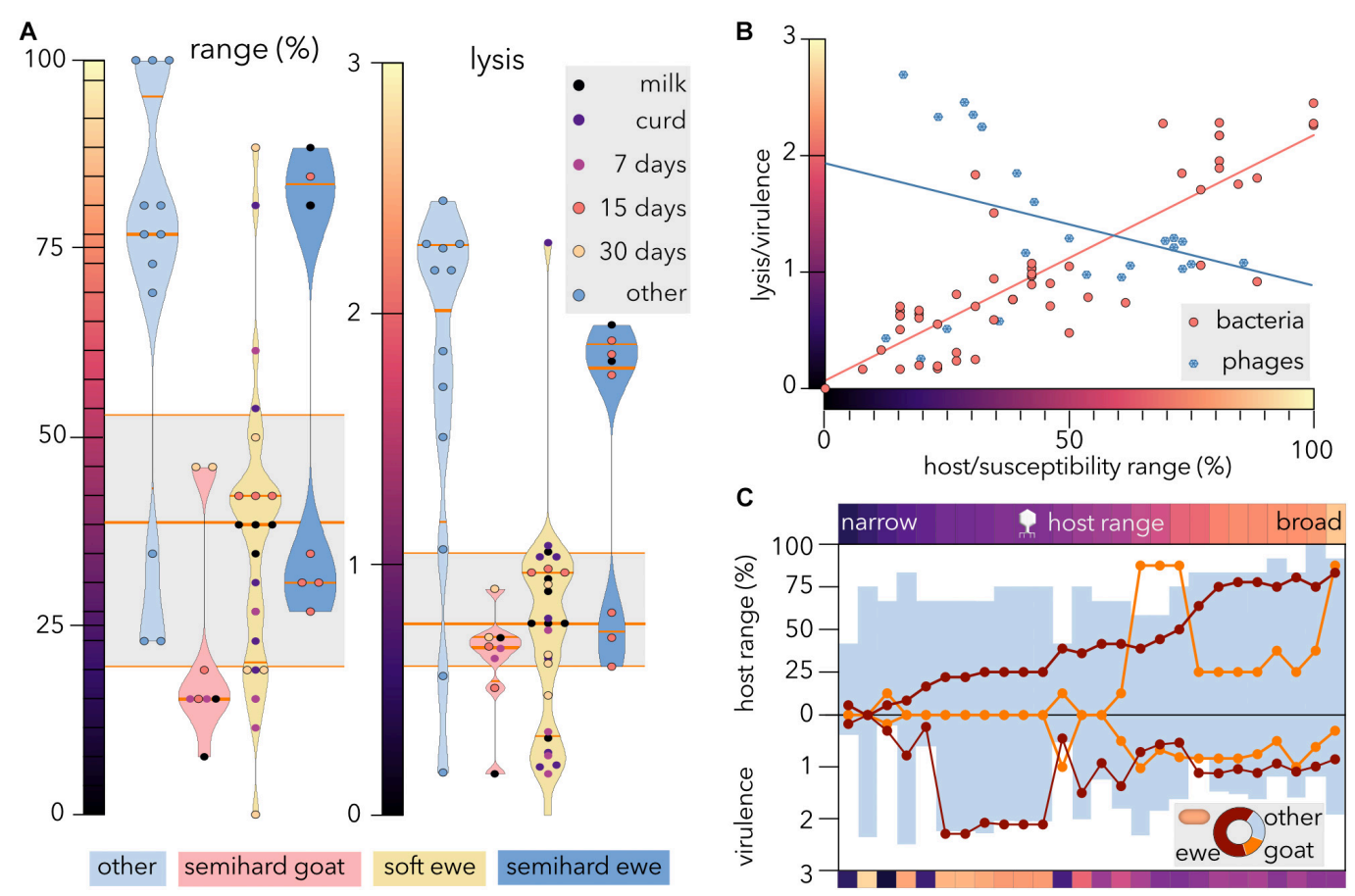

FIGURE 4 | Susceptibility, range and virulence of $E$. coli and coliphages. (A) Violin plots represent the distributions of $E$. coli susceptibility (left) and clearance intensity (right) for different coliphages. The median and quartiles are shown as orange lines. The gray box plots show the median and quartiles of all bacterial strains. Other, reference $E$. coli strains. (B) Comparison of host range versus virulence (phages) and susceptibility range versus lysis (bacteria). The linear regression for bacteria $\left(R^{2}=0.72\right)$ and phages $\left(R^{2}=0.1\right)$ is shown. (C) Characterization of virulence and host range of the coliphages. The phages were sorted by ascending host range from left to right, and the host range and virulence were broken down into three $E$. coli categories: ewe cheese-isolated (red dots), goat cheese-isolated (orange dots), and reference (other) strains (blue bars). The color bars represent the average host range (top) and virulence (bottom) of each phage as depicted in panel (B). The donut chart represents the proportion of each host category in the dataset.

a plateau, so phages with a host range above $50 \%$ produced intermediate bacterial clearance.

For an obligately lytic phage, there is no apparent advantage in lowering virulence, as the only way to successfully infect new cells is through lysis. However, a tradeoff exists between fecundity (burst size) and latent period because release of phage offspring involves the destruction of the machinery necessary to produce more phage particles. Consequently, higher host densities select faster proliferating phages with shorter phage latent periods but smaller burst sizes (Abedon et al., 2003). Additionally, to initiate reproduction, the viral genome must be "released" from the capsid into the cell and this requirement might entail a tradeoff between stability and virulence. Accordingly, the coliphage growth rate has been previously shown to correlate negatively with host range (Keen, 2014) and with extracellular stability (De Paepe and Taddei, 2006). Overall, abundant empirical data suggest that unlike the curse of the pharaoh hypothesis, phages suffer virulence/stability tradeoffs, so stable phages with broad host ranges tend to exploit their hosts sluggishly.

To investigate the differential performance in different groups of E. coli strains, the coliphages were sorted by their global host range (Figure 4B), and the average range and virulence for each host group were plotted (Figure 4C). Remarkably, broad host range phages were not the most virulent for any host group. Since approximately two-thirds (64.3\%) of the host dataset corresponded to ewe cheese isolates, the sorting of phages was expected to match partially with sorting by host-range values of this group. Strikingly, the average host range for reference strains never surpassed the value for ewe isolates. Although the high variability observed for goat isolates could be partially due to the smaller number of strains sampled, the differences with reference strains with a similar size might indicate diversifying selection in this particular niche. The adaptation of coliphages to withstand a particular stressor has been shown to produce negative epistatic interactions, reducing fitness when exposed to a different stressor (Heineman and Brown, 2012). These antagonistic pleiotropic effects might be explained by the small and compact genome of viruses, with some genes coding for multiple proteins that play different roles during their life cycle (Goldhill and Turner, 2014). Despite the modularity displayed for goat isolates, our results (Figures 3, 4C) reveal that ewe feces-isolated phages form a significantly nested network $\left(p\right.$-value $=10^{-7}$ ) when tested against different $E$. coli strains, as evidenced by the low temperature (17.35, where 100 is the maximum value) of the host-range matrix as described elsewhere (Molina et al., in submission). To further validate these results, we conducted a meta-analysis using data from this and other 34 studies of host-phage infection assays, representing 33,428 separate attempts to infect bacterial hosts from different sources (plants, livestock, dairy, sewage, seafood, and clinical isolates) with diverse phage strains. Strikingly, only 
3 (8.6\%) studies statistically fit the kill-the-winner model. These findings imply gene-for-gene coevolution and would explain why the phages isolated retain the ability to propagate on host strains from different niches. Likewise, a long-term coevolution study in a natural community (Laanto et al., 2017) showed that whereas phages evolved a broader host range over time, associated with increase in genome size, the bacteria were in general resistant against phages from the past but susceptible to infection by phages from contemporary and future time points. We are currently developing (Molina et al., in submission) a new method to design phage cocktails that takes into account network structure and will allow control of E. coli proliferation in cheesemaking. The inclusion of bacterial lineages from diverse sources will expectedly expand its applicability.

\section{CONCLUSION}

Our results are in agreement with the high bacterial diversity found in raw milk cheeses and with the high genomic diversity within the species $E$. coli, indicating that mixing multiple species of phages is required for the biocontrol of unwanted coliforms. Although broad host range phages are systematically surveyed during the formulation of phage cocktails, the evolutionary arms race with a highly versatile host such as E. coli, might provoke that the host range of coliphages is not necessarily a fixed property. Rather, it can show some plasticity and evolve over time. Moreover, broad host range phages face "life" history tradeoffs, such as lower virulence, which might be worth considering when selecting the candidates for biocontrol. Hence, different

\section{REFERENCES}

Abe, K., Yamamoto, S., and Shinagawa, K. (2002). Economic Impact of an Escherichia coli O157:H7 Outbreak in Japan. J. Food Prot. 65, 66-72. doi: 10.4315/0362-028x-65.1.66

Abedon, S. T., García, P., Mullany, P., and Aminov, R. (2017). Editorial: phage therapy: past, present and future. Front. Microbiol. 8:981. doi: 10.3389/fmicb. 2017.00981

Abedon, S. T., Hyman, P., and Thomas, C. (2003). Experimental examination of bacteriophage latent-period evolution as a response to bacterial availability. Appl. Environ. Microbiol. 69, 7499-7506. doi: 10.1128/aem.69.12.7499-7506. 2003

Abedon, S. T., and Yin, J. (2009). "Bacteriophage plaques: theory and analysis," in Bacteriophages Methods in Molecular Biology, eds M. R. J. Clokie and A. M. Kropinski (Totowa, NJ: Humana Press), 161-174. doi: 10.1007/978-1-60327164-6_17

Agrawal, A. F., and Lively, C. M. (2003). Modelling infection as a two-step process combining gene-for-gene and matching-allele genetics. Proc. R. Soc. Lond. B Biol. Sci. 270, 323-334. doi: 10.1098/rspb.2002.2193

Altekruse, S. F., Timbo, B. B., Mowbray, J. C., Bean, N. H., and Potter, M. E. (1998). Cheese-associated outbreaks of human illness in the United States, 1973 to 1992: sanitary manufacturing practices protect consumers. J. Food Prot. 61, 1405-1407. doi: 10.4315/0362-028x-61.10.1405

Andrews, B., and Fields, S. (2020). Distinct patterns of mutational sensitivity for $\lambda$ resistance and maltodextrin transport in Escherichia coli LamB. Microb. Genom. 6:364. doi: 10.1099/mgen.0.000364

Azevedo, M., Sousa, A., Moura de Sousa, J., Thompson, J. A., Proença, J. T., and Gordo, I. (2016). Trade-offs of Escherichia coli adaptation to an intracellular phage cocktail formulations might be required when devising long-term and short-term biocontrol strategies.

\section{DATA AVAILABILITY STATEMENT}

The raw data supporting the conclusions of this article will be made available by the authors, without undue reservation.

\section{AUTHOR CONTRIBUTIONS}

FM and JR conceived and designed the experiments. AS, RT, and AG performed the experiments. FM and AS analyzed the data. RT and IR provided the bacterial strains and the cheese samples; FM wrote the manuscript. All authors read and approved the final manuscript.

\section{FUNDING}

This work was partially supported by the grant GR18174 from the Extremadura Regional Goverment (Consejería de Economía, Ciencia y Agenda Digital, Junta de Extremadura).

\section{ACKNOWLEDGMENTS}

We are very grateful to Dr. MM for kindly providing bacteriophage samples. We also thank Encarna Ferrera for her excellent technical help.

lifestyle in macrophages. PLoS One 11:e146123. doi: 10.1371/journal.pone. 0146123

Balogh, B., Jones, J. B., Iriarte, F. B., and Momol, M. T. (2010). Phage therapy for plant disease control. Curr. Pharm. Biotechnol. 11, 48-57. doi: 10.2174/ 138920110790725302

Beckett, S. J., and Williams, H. T. P. (2013). Coevolutionary diversification creates nested-modular structure in phage-bacteria interaction networks. Interf. Focus 3:20130033. doi: 10.1098/rsfs.2013.0033

Bertozzi Silva, J., Storms, Z., and Sauvageau, D. (2016). Host receptors for bacteriophage adsorption. FEMS Microbiol. Lett. 363:fnw002. doi: 10.1093/ femsle/fnw002

Bohannan, B. J. M., and Lenski, R. E. (1999). Effect of prey heterogeneity on the response of a model food chain to resource enrichment. Am. Nat. 153, 73-82. doi: $10.1086 / 303151$

Bohannan, B. J. M., and Lenski, R. E. (2000). Linking genetic change to community evolution: insights from studies of bacteria and bacteriophage. Ecol. Lett. 3, 362-377. doi: 10.1046/j.1461-0248.2000.00161.x

Broniewski, J. M., Meaden, S., Paterson, S., Buckling, A., and Westra, E. R. (2020). The effect of phage genetic diversity on bacterial resistance evolution. ISME J. 14, 1-9. doi: 10.1038/s41396-019-0577-7

Callon, C., Arliguie, C., and Montel, M.-C. (2016). Control of Shigatoxinproducing Escherichia coli in cheese by dairy bacterial strains. Food Microbiol. 53, 63-70. doi: 10.1016/j.fm.2015.08.009

Casey, E., Mahony, J., Neve, H., Noben, J.-P., Dal Bello, F., and van Sinderen, D. (2015). Novel phage group infecting Lactobacillus delbrueckii subsp. lactis, as revealed by genomic and proteomic analysis of bacteriophage Ldl1. Appl. Environ. Microbiol. 81, 1319-1326. doi: 10.1128/AEM.03 413-14 
Chan, B. K., Sistrom, M., Wertz, J. E., Kortright, K. E., Narayan, D., and Turner, P. E. (2016). Phage selection restores antibiotic sensitivity in MDR Pseudomonas aeruginosa. Sci. Rep. 6, 1-8. doi: 10.1038/srep26717

Chang, G. W. G., Brill, J. J., and Lum, R. R. (1989). Proportion of beta-Dglucuronidase-negative Escherichia coli in human fecal samples. Appl. Environ. Microbiol. 55, 335-339. doi: 10.1128/aem.55.2.335-339.1989

Chatterjee, S., and Rothenberg, E. (2012). Interaction of Bacteriophage $\lambda$ with its E. coli receptor, LamB. Viruses 4, 3162-3178. doi: 10.3390/v4113162

Coleman, W. G. J., Goebel, P. J., and Leive, L. (1977). Genetic analysis of Escherichia coli O111:B4, a strain of medical and biochemical interest. J. Bacteriol. 130, 656-660. doi: 10.1128/jb.130.2.656-660.1977

Common, J., Morley, D., Westra, E. R., and van Houte, S. (2019). CRISPRCas immunity leads to a coevolutionary arms race between Streptococcus thermophilus and lytic phage. Philos. Trans. R. Soc. B Biol. Sci. 374:98. doi: 10.1098/rstb.2018.0098

Cox, A. M. (2003). The death of lord carnarvon. Lancet 361:1994. doi: 10.1016/ S0140-6736(03)13576-3

Cress, B. F., Greene, Z. R., Linhardt, R. J., and Koffas, M. A. G. (2013). Draft genome sequence of Escherichia coli strain ATCC 23506 (Serovar O10:K5:H4). Genome Announc. 1:737. doi: 10.1128/genomeA.00049-13

De Paepe, M., and Taddei, F. (2006). Viruses' life history: towards a mechanistic basis of a trade-off between survival and reproduction among phages. PLoS Biol. 4:e193. doi: 10.1371/journal.pbio.0040193

Delbès-Paus, C., Miszczycha, S., Ganet, S., Helinck, S., Veisseire, P., Pochet, S., et al. (2013). Behavior of Escherichia coli O26:H11 in the presence of Hafnia alvei in a model cheese ecosystem. Int. J. Food Microbiol. 160, 212-218. doi: 10.1016/j.ijfoodmicro.2012.10.019

Feng, P., Lum, R., and Chang, G. W. (1991). Identification of uidA gene sequences in beta-D-glucuronidase-negative Escherichia coli. Appl. Environ. Microbiol. 57, 320-323. doi: 10.1128/aem.57.1.320-323.1991

Flores, C. O., Meyer, J. R., Valverde, S., Farr, L., and Weitz, J. S. (2011). Statistical structure of host-phage interactions. Proc. Natl. Acad. Sci. U.S.A. 108, E288E297. doi: 10.1073/pnas.1101595108

Fogg, P. C. M., Allison, H. E., Saunders, J. R., and McCarthy, A. J. (2010). Bacteriophage lambda: a paradigm revisited. J. Virol. 84, 6876-6879. doi: 10. 1128/JVI.02177-09

Fong, K., Tremblay, D. M., Delaquis, P., Goodridge, L., Levesque, R. C., Moineau, S., et al. (2019). Diversity and host specificity revealed by biological characterization and whole genome sequencing of bacteriophages infecting Salmonella enterica. Viruses 11:854. doi: 10.3390/v11090854

Fortuna, M. A., Barbour, M. A., Zaman, L., Hall, A. R., Buckling, A., and Bascompte, J. (2019). Coevolutionary dynamics shape the structure of bacteria-phage infection networks. Evolution 73, 1001-1011. doi: 10.1111/evo. 13731

Frampton, E. W., and Restaino, L. (1993). Methods for Escherichia coli identification in food, water and clinical samples based on beta-glucuronidase detection. J. Appl. Bacteriol. 74, 223-233. doi: 10.1111/j.1365-2672.1993. tb03019.x

Fraser, J. S., Yu, Z., Maxwell, K. L., and Davidson, A. R. (2006). Ig-Like domains on bacteriophages: a tale of promiscuity and deceit. J. Mol. Biol. 359, 496-507. doi: 10.1016/j.jmb.2006.03.043

Freitas, A. C., Pais, C., Malcata, F. X., and Hogg, T. A. (1996). Microbiological characterization of picante da beira baixa cheese. J. Food Prot. 59, 155-160. doi: 10.4315/0362-028X-59.2.155

Gabig, M., Herman-Antosiewicz, A., Kwiatkowska, M., Los, M., Thomas, M. S., and Wegrzyn, G. (2002). The cell surface protein Ag43 facilitates phage infection of Escherichia coli in the presence of bile salts and carbohydrates. Microbiology 148, 1533-1542. doi: 10.1099/00221287-148-5-1533

Gallet, R., Kannoly, S., and Wang, I.-N. (2011). Effects of bacteriophage traits on plaque formation. BMC Microbiol. 11:181. doi: 10.1186/1471-2180-11-181

Gallet, R., Shao, Y., and Wang, I.-N. (2009). High adsorption rate is detrimental to bacteriophage fitness in a biofilm-like environment. BMC Evol. Biol. 9:241. doi: 10.1186/1471-2148-9-241

Gandon, S. (1998). The curse of the pharaoh hypothesis. Proc. R. Soc. Lond. B Biol. Sci. 265, 1545-1552. doi: 10.1098/rspb.1998.0470

Gaya, P., Medina, M., and Nuñez, M. (1987). Enterobacteriaceae, coliforms, faecal coliforms and salmonellas in raw ewes' milk. J. Appl. Bacteriol. 62, 321-326. doi: $10.1111 /$ j.1365-2672.1987.tb04927.x
Goldhill, D. H., and Turner, P. E. (2014). ScienceDirect the evolution of life history trade-offs in viruses. Curr. Opin. Virol. 8, 79-84. doi: 10.1016/j.coviro.2014.07. 005

González, R. D., Tamagnini, L. M., Olmos, P. D., and de Sousa, G. B. (2003). Evaluation of a chromogenic medium for total coliforms and Escherichia coli determination in ready-to-eat foods. Food Microbiol. 20, 601-604. doi: 10.1016/ S0740-0020(02)00178-8

Gordienko, E. N., Kazanov, M. D., and Gelfand, M. S. (2013). Evolution of pangenomes of Escherichia coli. Shigella spp., and Salmonella enterica. J. Bacteriol. 195, 2786-2792. doi: 10.1128/JB.02285-12

Grad, Y. H., Lipsitch, M., Feldgarden, M., Arachchi, H. M., Cerqueira, G. C., FitzGerald, M., et al. (2012). Genomic epidemiology of the Escherichia coli O104:H4 outbreaks in Europe, 2011. Proc. Natl. Acad. Sci. U.S.A. 109, 30653070. doi: 10.1073/pnas.1121491109

Guggisberg, D., Schuetz, P., Winkler, H., Amrein, R., Jakob, E., Fröhlich-Wyder, M.-T., et al. (2015). Mechanism and control of the eye formation in cheese. Intern. Dairy J. 47, 118-127. doi: 10.1016/j.idairyj.2015.03.001

Hantke, K. (2020). Compilation of Escherichia coli K-12 outer membrane phage receptors - their function and some historical remarks. FEMS Microbiol. Lett. 367:1116. doi: 10.1093/femsle/fnaa013

Heineman, R. H., and Brown, S. P. (2012). Experimental evolution of a bacteriophage virus reveals the trajectory of adaptation across a fecundity/ longevity trade-off. PLoS One 7:e46322. doi: 10.1371/journal.pone.0046322

Hendrickson, H. (2009). Order and disorder during Escherichia coli divergence. PLoS Genet. 5:e1000335. doi: 10.1371/journal.pgen.1000335

Hyman, P., and Abedon, S. T. (2010). Bacteriophage host range and bacterial resistance. Adv. Appl. Microbiol. 70, 217-248. doi: 10.1016/s0065-2164(10) 70007-1

Jackman, P. J. H. (1988). “5 Microbial systematics based on electrophoretic wholecell protein patterns," in Current Methods for Classification and Identification of Microorganisms Methods in Microbiology, eds R. R. Colwell and R. Grigorova (Cambridge, MA: Academic Press), 209-225. doi: 10.1016/s0580-9517(08) 70411-2

Keen, E. C. (2014). Tradeoffs in bacteriophage life histories. Bacteriophage 4:e28365. doi: 10.4161/bact.28365

Laanto, E., Hoikkala, V., Ravantti, J., and Sundberg, L.-R. (2017). Long-term genomic coevolution of host-parasite interaction in the natural environment. Nat. Comms. 8:111. doi: 10.1038/s41467-017-00158-7

Laemmli, U. K. (1970). Cleavage of structural proteins during the assembly of the head of bacteriophage T4. Nature 227, 680-685. doi: 10.1038/227680a0

Lenski, R. E. (1988). Experimental studies of pleiotropy and epistasis in Escherichia coli. I. variation in competitive fitness among mutants resistant to virus T4. Evolution 42:425. doi: 10.2307/2409028

Lukjancenko, O., Wassenaar, T. M., and Ussery, D. W. (2010). Comparison of 61 sequenced Escherichia coli genomes. Microb. Ecol. 60, 708-720. doi: 10.1007/ s00248-010-9717-3

Maynard, N. D., Birch, E. W., Sanghvi, J. C., Chen, L., Gutschow, M. V., and Covert, M. W. (2010). A Forward-genetic screen and dynamic analysis of lambda phage host-dependencies reveals an extensive interaction network and a new anti-viral strategy. PLoS Genet. 6:e1001017. doi: 10.1371/journal.pgen.1001017

Mirzaei, M. K., and Nilsson, A. S. (2015). Isolation of phages for phage therapy: a comparison of spot tests and efficiency of plating analyses for determination of host range and efficacy. PLoS One 10:e0118557. doi: 10.1371/journal.pone. 0118557

Molina, F., Jimenez-Sanchez, A., and Guzmán, E. C. (1998). Determining the optimal thymidine concentration for growing Thy- Escherichia coli strains. J. Bacteriol. 180, 2992-2994. doi: 10.1128/jb.180.11.2992-2994.1998

Molina, F., López-Acedo, E., Tabla, R., Roa, I., Gómez, A., and Rebollo, J. E. (2015). Improved detection of Escherichia coli and coliform bacteria by multiplex PCR. BMC Biotechnol. 15:48. doi: 10.1186/s12896-015-0168-2

Montel, M.-C., Buchin, S., Mallet, A., Delbes-Paus, C., Vuitton, D. A., Desmasures, N., et al. (2014). Traditional cheeses: rich and diverse microbiota with associated benefits. Int. J. Food Microbiol. 177, 136-154. doi: 10.1016/j.ijfoodmicro.2014. 02.019

Muniesa, M., Lucena, F., and Jofre, J. (1999). Study of the potential relationship between the morphology of infectious somatic coliphages and their persistence in the environment. J. Appl. Microbiol. 87, 402-409. doi: 10.1046/j.1365-2672. 1999.00833.x 
Muniesa, M., Mocé-Llivina, L., Katayama, H., and Jofre, J. (2002). Bacterial host strains that support replication of somatic coliphages. Antonie Van Leeuwenhoek 83, 305-315.

Official Journal of the European Union [OJEU] (2002). Publication of an Application for Registration Pursuant to Article 6(2) of Council Regulation (EEC) No 2081/92 on the Protection of Geographical Indications and Designations of Origin (2002/C 291/02). Available online at: https://eur-lex.europa.eu/ LexUriServ/LexUriServ.do?uri=OJ:C:2002:291:0002:0004:EN:PDF

Official Journal of the European Union [OJEU] (2004). Publication of an Application for Registration Pursuant to Article 6(2) of Council Regulation (EEC) No 2081/92 on the Protection of Geographical Indications and Designations of Origin (2004/C 58/07). Available online at: https://eur-lex.europa.eu/legalcontent/EN/TXT/?uri=CELEX:52004XC0306(06)

O'Sullivan, O., and Cotter, P. D. (2017). "Chapter 12 - Microbiota of raw milk and raw milk cheeses," in Cheese Chemistry, Physics and Microbiology, eds L. H. P. McSweeney, P. F. Fox, and D. W. Everett 4th Edn (Amsterdam: Elsevier Ltd).

Pagnout, C., Sohm, B., Razafitianamaharavo, A., Caillet, C. X. L., Offroy, M., Leduc, M., et al. (2019). Pleiotropic effects of rfa-gene mutations on Escherichia coli envelope properties. Sci. Rep. 9, 1-16. doi: 10.1038/s41598-019-46100-3

Pujato, S. A., Quiberoni, A., and Mercanti, D. J. (2018). Bacteriophages on dairy foods. J. Appl. Microbiol. 126, 14-30. doi: 10.1111/jam. 14062

Rahmouni, O., Vignal, C., Titécat, M., Foligné, B., Pariente, B., Dubuquoy, L., et al. (2018). High carriage of adherent invasive E. coli in wildlife and healthy individuals. Gut Pathog. 10:23. doi: 10.1186/s13099-0180248-7

Randall, L. L. (1975). Quantitation of the loss of the bacteriophage lambda receptor protein from the outer membrane of lipopolysaccharide-deficient strains of Escherichia coli. J. Bacteriol. 123, 41-46. doi: 10.1128/jb.123.1.41-46.1975

Rasko, D. A., Rosovitz, M. J., Myers, G. S. A., Mongodin, E. F., Fricke, W. F., Gajer, P., et al. (2008). The pangenome structure of Escherichia coli: comparative genomic analysis of E. coli commensal and pathogenic isolates. J. Bacteriol. 190, 6881-6893. doi: 10.1128/JB.00619-08

Raynal-Ljutovac, K., Lagriffoul, G., Paccard, P., Guillet, I., and Chilliard, Y. (2008). Composition of goat and sheep milk products: an update. Small Ruminant Res. 79, 57-72. doi: 10.1016/j.smallrumres.2008.07.009

Roche, B., Drake, J. M., and Rohani, P. (2011). The curse of the Pharaoh revisited: evolutionary bi-stability in environmentally transmitted pathogens. Ecol. Lett. 14, 569-575. doi: 10.1111/j.1461-0248.2011.01619.x

Ross, A., Ward, S., and Hyman, P. (2016). More is better: selecting for broad host range bacteriophages. Front. Microbiol. 7:1352. doi: 10.3389/fmicb.2016 01352

Rotman, E., Amado, L., and Kuzminov, A. (2010). Unauthorized horizontal spread in the laboratory environment: the tactics of lula, a temperate lambdoid bacteriophage of Escherichia coli. PLoS One 5:e11106. doi: 10.1371/journal. pone.0011106

Sambrook, J. F., and Russell, D. W. (2001). Molecular Cloning: A Laboratory Manual. Cold Spring Harbor, NY: Cold Spring Harbor Laboratory Press.
Sen, K., and Nikaido, H. (1991). Lipopolysaccharide structure required for in vitro trimerization of Escherichia coli OmpF porin. J. Bacteriol. 173, 926-928. doi: 10.1128/jb.173.2.926-928.1991

Shabana, I., Bouqellah, N. A., and Albakri, N. N. (2020). Comparative metagenomic analysis of small ruminants' fecal microbiota. Research Square [Preprint], doi: $10.21203 / \mathrm{rs} .2 .21081 / \mathrm{v} 1$

Sommer, S., Boudsocq, F., Devoret, R., and Bailone, A. (1998). Specific RecA amino acid changes affect RecA-UmuD'C interaction. Mol. Microbiol. 28, 281-291. doi: 10.1046/j.1365-2958.1998.00803.x

Storms, Z. J., and Sauvageau, D. (2015). Modeling tailed bacteriophage adsorption_ Insight into mechanisms. Virology 485, 355-362. doi: 10.1016/j.virol.2015.08.007

Tabla, R., Gómez, A., Simancas, A., Rebollo, J. E., Molina, F., and Roa, I. (2016). Enterobacteriaceae species during manufacturing and ripening of semi-hard and soft raw ewe's milk cheese: gas production capacity. Small Rumin. Res. 145, 123-129. doi: 10.1016/j.smallrumres.2016.11.008

Tabla, R., Gómez, A., Simancas, A., Rebollo, J. E., Molina, F., and Roa, I. (2018). Early blowing in raw goats' milk cheese: gas production capacity of Enterobacteriaceae species present during manufacturing and ripening. J. Dairy Res. 85, 331-338. doi: 10.1017/S0022029918000511

Tornadijo, E., Fresno, J. M., Carballo, J., and Martín-Sarmiento, R. (1993). Study of Enterobacteriaceae throughout the manufacturing and ripening of hard goats' cheese. J. Appl. Bacteriol. 75, 240-246. doi: 10.1111/j.1365-2672.1993.tb02772.x

Turner, K. M., Restaino, L., and Frampton, E. W. (2000). Efficacy of chromocult coliform agar for coliform and Escherichia coli detection in foods. J. Food Prot. 63, 539-541. doi: 10.4315/0362-028x-63.4.539

Weitz, J. S., Poisot, T., Meyer, J. R., Flores, C. O., Valverde, S., Sullivan, M. B. et al. (2013). Phage-bacteria infection networks. Trends Microbiol. 21, 82-91. doi: 10.1016/j.tim.2012.11.003

Yamada, H., Nogami, T., and Mizushima, S. (1981). Arrangement of bacteriophage lambda receptor protein $(\mathrm{LamB})$ in the cell surface of Escherichia coli: a reconstitution study. J. Bacteriol. 147, 660-669. doi: 10.1128/jb.147.2.660-669. 1981

Zago, M., Bonvini, B., Martín Platero, A. M., Mucchetti, G., Carminati, D., and Giraffa, G. (2007). Characterisation of Escherichia coli isolated from raw milk cheeses. Anna. Microbiol. 57:49. doi: 10.1007/bf03175049

Conflict of Interest: The authors declare that the research was conducted in the absence of any commercial or financial relationships that could be construed as a potential conflict of interest.

Copyright (c) 2020 Molina, Simancas, Tabla, Gómez, Roa and Rebollo. This is an open-access article distributed under the terms of the Creative Commons Attribution License (CC BY). The use, distribution or reproduction in other forums is permitted, provided the original author(s) and the copyright owner(s) are credited and that the original publication in this journal is cited, in accordance with accepted academic practice. No use, distribution or reproduction is permitted which does not comply with these terms. 